\title{
A DIDÁTICA PROFISSIONAL (DP) ARTICULADA À TEORIA DAS SITUAÇÕES DIDÁTICAS (TSD) NA FORMAÇÃO DO PROFESSOR DE MATEMÁTICA NO BRASIL: O CASO DE UMA SITUACÇÃO DIDÁTICA DIRECIONADA AO SPAECE
}

\author{
The Professional Didactics (PD) articulated to the Theory of Didactical Situations (TDS) \\ in the formation of Mathematics teacher in Brazil: the case of a teaching situation \\ directed to SPAECE
}

\author{
Aline Maria da Silva Camilo* \\ Francisco Régis Vieira Alves** \\ Francisca Cláudia Fernandes Fontenele ${ }^{* * *}$
}

Resumo: Este trabalho enfatiza uma discussão acerca da formação do professor, no cenário educacional brasileiro, através da vertente francesa Didática Profissional, aliada à Teoria das Situações Didáticas. O contributo metodológico da pesquisa apresentou-se através da Engenharia Didática de Formação (ou Engenharia Didática de 2a geração), criada a partir da Engenharia Didática clássica, todavia voltada exclusivamente para a observação da prática e formação docente. Trata-se de uma reunião de estudos bibliográficos, retirados de trabalhos anteriores, nos quais trataram o mesmo tema, construindo assim um conjunto de aspectos teóricos metodológicos introdutórios de uma futura pesquisa de mestrado. Nesse sentido, temse que a Didática Profissional engloba, nesse contexto, a análise profissional do professor, especialmente o de matemática, seja na sala de aula, na escola ou na instituição escolar, bem como suas concepções pragmáticas e epistêmicas que o acompanham ao longo do percurso profissional. Ademais, apresenta-se uma situação didática, elaborada por meio de uma questão, retirada do boletim pedagógico de avaliação de matemática do Sistema Permanente de Avaliação da Educação Básica do Ceará (SPAECE), uma vez que este trabalho pretende utilizar tal exame como parâmetro de concepção da situação didática sugerida. Por fim, explora-se os recursos do software GeoGebra para visualização e manipulação dos elementos gráficos,

\footnotetext{
* Licenciada em Matemática pela Universidade Federal do Ceará (UFC). Especialista em Educação a Distância pela Universidade Estadual do Ceará (UECE). Mestranda em Ensino de Ciências e Matemática pelo Instituto Federal de Educação, Ciência e Tecnologia do Ceará (IFCE). Professora da Educação Básica da Secretaria de Educação do Estado do Ceará. Orcid id: https://orcid.org/0000-0003-4403-8951. E-mail: allynecamilo@hotmail.com.

** Mestre em Matemática Pura pela Universidade Federal do Ceará (2001) e em Educação, com ênfase em Educação Matemática, pela Universidade Federal do Ceará (2002). Doutor com ênfase no ensino de Matemática (UFC - 2011). Professor Titular do departamento de Matemática do Instituto Federal de Educação, Ciência e Tecnologia do Estado do Ceará - IFCE. Bolsista de Produtividade do Conselho Nacional de Desenvolvimento Científico e Tecnológico -CNPQ - PQ2. Coordenador do Programa de Pós-Graduação em Ensino de Ciências e Matemática do Instituto Federal de Educação, Ciência e Tecnologia do Ceará - PGECM/IFCE. Docente permanente do Programa de Pós-Graduação do Mestrado Profissional em Educação Profissional Tecnológica PROFPT/IFCE. Orcid id: https://orcid.org/0000-0003-3710-1561. E-mail: fregis@ ifce.edu.br.
}

\footnotetext{
*** Licenciada em Matemática. Mestre e Doutora em Educação pela Faculdade de Educação da Universidade Federal do Ceará (UFC), na linha de Pesquisa de Educação, Currículo e Ensino. Pós-doutoranda em Educação Profissional e Tecnológica. Professora Assistente do curso de Licenciatura em Matemática da Universidade Estadual Vale do Acaraú (UVA). Orcid id: https://orcid.org/0000-0002-1825-7272. E-mail: claudiafontenele05@gmail.com.
} 
favorecendo uma melhor compreensão durante o processo de resolução da situação-problema proposta.

Palavras-chave: Didática Profissional. Formação. Ensino. Trabalho.

\begin{abstract}
This work emphasizes a discussion about teacher education in the Brazilian educational scenario, through the French approach of Professional Didactics, combined with the Theory of Didactic Situations. The methodological contribution of this research was presented through Didactic Engineering of Training (or Didactic Engineering of 2nd generation), created from classical Didactic Engineering, however it was focused exclusively on the observation of practice and teacher training. It is a collection of bibliographic studies, drawn from previous works, in which they addressed the same theme, thus building a set of introductory methodological theoretical aspects of a future master's research. In this sense, Professional Didactics encompasses, in context, the professional analysis of the teacher, especially The Mathematics one, in the classroom, at school or in the school institution, as well as his pragmatic and epistemic conceptions that follow him along the professional path. Furthermore, a didactic situation is presented, elaborated through a question, taken from the pedagogical bulletin of evaluation of mathematics of the Permanent System of Evaluation of Basic Education of Ceará (SPAECE), since this work intends to use such exam as a parameter of conception of the suggested didactic situation. Finally, the resources offered by GeoGebra software to visualization and manipulation of graphic elements are explored, favoring a better comprehension during the process of solving the proposed problem-situation.
\end{abstract}

Keywords: Professional Didactics. Formation. Teaching. Job.

\title{
1 Introdução
}

Antes de adentrar no cenário acadêmico nacional, convém explanar, num contexto internacional, acerca de um processo de ascensão, integrado aos estudos e investigações acadêmicas, atinentes à educação matemática, denominada, segundo Alves e Dias (2017), de Didática da Matemática (DM). De acordo com Alves (2016a), este processo de mudanças originou-se na França, ao final dos anos 60, onde ocorria ali uma grande efervescência intelectual constituída, predominantemente, por componentes do locus acadêmico, na busca de profundas melhorias no sistema de ensino do país, com uma acentuada atenção voltada para o ensino da matemática. Douady (1995) relata que simultaneamente a tal efervescência, verificou-se também uma manifestação para a renovação nos currículos matemáticos, gerando assim a necessidade de fornecer a capacitação complementar aos professores de matemática, uma vez que estes não estavam acostumados com a nova metodologia. Com isso, tornou-se imprescindível uma abordagem científica aos problemas inseridos no ensino matemático e às relações de ensino e aprendizagem, na perspectiva de uma transposição didática, levando-se em conta a interação e dependência entre professor, aluno e saber.

Doravante, no cenário brasileiro, conforme Alves e Dias (2017), ainda que, desde meados dos anos 80 e 90, tenha se registrado uma forte influência investigativa sobre o processo de ensino e aprendizagem da matemática, advinda da DM, e uma conquista da rigidez técnica e científica em tais pesquisas, infelizmente não enxerga-se tal mudança, efetiva e concreta, aplicada dentro da sala de aula. Com efeito, Moreira (2004) expõe que, apesar de existir no Brasil várias produções científicas na área da educação em matemática, realizada pela comunidade de pesquisadores, estas ainda não foram suficientes para causarem um impacto 
significativo no ambiente escolar, especialmente na sala de aula. Não obstante, é possível depreender que, de certo modo, o propulsor social central e operante de um abundante conjunto de teorias e de modelos refletidos à transposição didática em sala de aula, apontada na interação anterior, é o professor. Assim, desse ponto de vista, é possível expender que a qualidade da formação inicial e continuada do professor de matemática tem grande influência nesta situação de inabilidade, morosidade e estagnação dos resultados reais, provenientes da tenacidade científica aplicada ao longo dos anos por vários especialistas do país. (ALVES; DIAS, 2017).

Por conseguinte, na perspectiva da pesquisa em Educação Matemática no Brasil (ALVES; DIAS, 2017), adentra-se em uma abordagem ligada ao processo de formação docente, considerando sua dimensão epistêmica, disciplinar e pragmática da inserção de conhecimentos profissionais e situacionais, que contribuem para o alcance de uma competência profissional para o ensino, sobretudo da matemática. Nesse sentido, com o propósito da utilização de uma sistemática investigativa, acerca do papel profissional do professor, o presente trabalho recorre a alguns quadros teóricos, oriundos da França entre as décadas de 80 e 90 . O primeiro se constitui a partir da Teoria das Situações Didáticas (TSD), desenvolvida por Guy Brousseau (2002; 2008), tendo a situação didática como objeto principal de estudo, possibilitando, por sua vez, a identificação da interação entre professor, aluno e saber. O segundo quadro de referência diz respeito à Engenharia Didática de Formação (EDF), resultante da necessidade da inclusão do professor, na investigação didática, desenvolvida a priori, pela Engenharia Didática Clássica (ED) (PERRIN-GLORIAN; BELLEMAIN, 2019). Por fim, o último quadro teórico refere-se à Didática Profissional (DP), que abrange o cenário ocupacional de ação e inserção do adulto, enquanto profissional, inclusive a do professor, visto que este é considerado como uma espécie de "operário da educação" e, consequentemente, um trabalhador e um relevante agente social (ALVES; JUCÁ, 2019, p. 106).

O referido estudo evidencia uma pesquisa de abordagem qualitativa, com base em estudos bibliográficos, a partir de autores como Brousseau (2002; 2008), Pastré (2004; 2011), Pastré, Mayen e Vergnaud (2006), Alves (2016a; 2016b; 2018a; 2018b; 2019), (pioneiro nos trabalhos aplicados à DP no Brasil, especialmente com repercussão na matemática), dentre outros. Isso posto, este artigo tem o objetivo de realizar uma discussão sobre a prática do professor de matemática, diante da apresentação de uma situação didática profissional (SDP), concebida a partir de uma dinâmica, organizada pelos pressupostos da EDF e fundamentada pela articulação entre a DP e a TSD.

A situação didática proposta será direcionada à avaliação externa, realizada no estado do Ceará: o Sistema Permanente de Avaliação da Educação Básica do Ceará (SPAECE). O SPAECE é uma prova aplicada desde 1992, padronizada e em larga escala, avaliando atualmente todos os alunos da rede pública de ensino, no nível de leitura para o $2^{\circ}$ ano do ensino fundamental, e nas disciplinas de português e matemática para o $5^{\circ}$ e $9^{\circ}$ ano, também do ensino fundamental, $3^{\circ}$ ano do ensino médio e EJA (Educação de Jovens e Adultos). A matriz de referência de matemática envolve quatro temas, a saber: Interagindo com números e funções, Convivendo com a Geometria, Vivenciando as medidas, e Tratamento da informação.

Por fim, introduz-se uma abordagem ao uso do GeoGebra como adjutório na exposição da situação didática. O Geogebra é um software gratuito que auxilia na compreensão e manipulação dos elementos durante a resolução do problema, pois a visualização das figuras geométricas, por meio do aplicativo, "além de promover a intuição geométrica, auxilia na redução da abstração dos conceitos matemáticos" (PAIVA; ALVES, 2018, p. 72). 


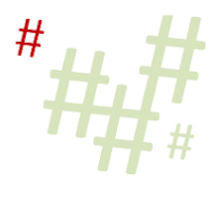

Destarte, nas seções vindouras, abordar-se-á algumas conjecturas dos principais referenciais teóricos que fundamentam o desenvolvimento deste trabalho e que consubstanciam uma identidade profissional para o professor de matemática.

\section{Teoria das Situações Didáticas (TSD)}

O planejamento compreende em sistematizar o trabalho do professor, aspirando contribuir para o desenvolvimento de competências e habilidades que propiciem o processo de aprendizagem do aluno. Brousseau (2002) declara que os matemáticos não transmitem seus resultados da forma em que os descobrem, eles os reorganizam e dão a eles a forma mais geral possível. "Eles procuram situações que possam dar sentido ao conhecimento a ser ensinado" (BROUSSEAU, 2002, p. 227). Assim, define-se por situação didática:

O conjunto de relações estabelecidas explicitamente e/ou implicitamente entre um aluno ou grupo de alunos, um certo milieu (contendo eventualmente instrumentos ou objetos) e um sistema educativo (o professor) para que esses alunos adquiram um saber constituído ou em constituição (BROUSSEAU, 1978 apud ALMOULOUD 2007, p. 33).

Segundo Perrin-Glorian e Bellemain (2019), as situações devem considerar a organização da matemática, as oportunidades de aprendizagem dos estudantes e as circunstâncias da prática docente dos professores. Brousseau (2008) afirma que o processo didático não deve limitar-se apenas à conduta do professor, estas circunstâncias devem ser associadas permanentemente à interação entre professor e aluno, inseridos em um meio (milieu), onde decorre a transição de conhecimento em saber. A situação adidática, ainda conforme o autor, é caracterizada como uma situação pensada, organizada e instituída pelo professor, porém não revelada para seus alunos a sua intenção pedagógica, com o propósito de propiciar circunstâncias favoráveis à incorporação do conhecimento sobre aquilo que se deseja ensinar. Assim, no processo de ensino e aprendizagem, em alguns momentos (situação adidática), os alunos deverão agir de forma independente, sem qualquer intervenção do professor no fornecimento de respostas, utilizando por si mesmo o saber (BROUSSEAU, 2002).

Desta forma, Brousseau (2002) desenvolveu etapas para as situações didáticas, cada uma com suas particularidades e relações distintas com o saber. São elas:

a) Dialética da ação: "sucessão de interações entre o aluno e o meio" (BROUSSEAU, 2002, p. 9), realizando estratégias racionais ou intuitivas para chegar à resolução do problema;

b) Dialética da formulação: ocasião em que ocorre a troca de informações entre o aluno (já ciente do problema) e o meio, utilizando-se de uma linguagem compreensível para todos os envolvidos (BROUSSEAU, 2002);

c) Dialética da validação: situação em que o estudante deverá demonstrar a validade de suas afirmações construindo teorias, de forma a fornecer razões para convencer o interlocutor ou aceitar outras para mudar de opinião (BROUSSEAU, 2008).

d) Dialética da institucionalização: momento em que "o professor fixa convencionalmente e explicitamente o estatuto cognitivo do saber" (ALMOULOUD, 2007, p. 40).

Deste modo, com a realização de situações didáticas que efetivamente proporcionam o funcionamento do saber e dos conhecimentos aferentes, ou seja, não transformáveis ou não transformados em saberes, Brousseau (2008, p. 91) define o processo de devolução como o "ato pelo qual o professor faz com que o aluno aceite a responsabilidade de uma situação de 
aprendizagem (adidática) ou de um problema e assume ele mesmo as consequências dessa transferência". Ainda tratando-se do conhecimento, Alves e Catarino (2019) observam que, na cultura francófona, encontra-se uma diferenciação entre a natureza e função exercida do conhecimento epistêmico disciplinar e científico (connaissance) do conhecimento técnico, apresentado formalmente em sala de aula pelo professor (savoir). Para melhor compreensão, a figura a seguir representa a dialética entre conhecimento e saber, caracterizando a situação de institucionalização, outrora já mencionada.

Figura 1 - Processo dialético entre conhecimento (connaissance) e saber (savoir)

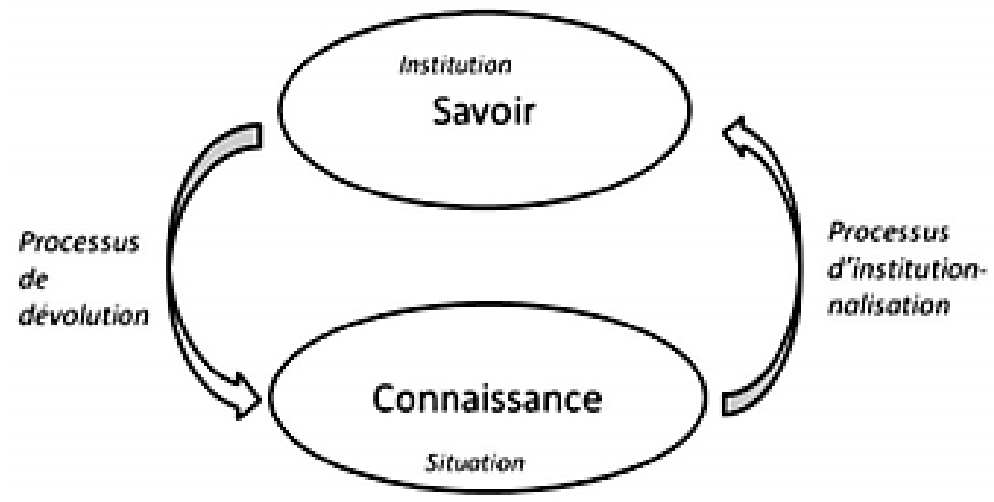

Fonte: Margolinas, 2015, p. 34.

Contudo, atenta-se que a TSD desconsidera um olhar altamente relevante, peculiar ao papel do docente, que é o processo de aprendizagem do professor de matemática em seu próprio local de trabalho e o desenvolvimento de suas capacidades laborais, perante desafios (ALVES, 2018b). Portanto, a caráter de complementaridade à Teoria das Situações Didáticas, apresentase a seguir uma breve discussão acerca de alguns pressupostos da Didática Profissional.

\section{Didática Profissional (DP)}

Uma das principais mudanças que contribuíram para o impulso do estudo da Didática Profissional (DP) foi o redirecionamento do foco de atenção acerca da performance dos princípios indispensáveis para a efetivação de tarefas complexas e primordiais no ambiente de trabalho (CARAMELO; SANTOS, 2013). Durante o período taylloriano, atribuíam maior importância ao sujeito (trabalhador) individual e relacionavam a competência profissional ao saber fazer, ou seja, o profissional competente era aquele que sabia executar e processar tarefas predeterminadas. Contudo, devido à crise desta perspectiva taylloriana no campo do trabalho, expandiu-se o conceito de competência para, além de saber fazer, saber entender e saber combinar (HATCHUEL; WEIL, 1992 apud PASTRÉ, 2004). Savoyant (1996 apud Alves, 2019) descreve que também se almejava, sobre o campo de trabalho, um cenário profissional de caráter coletivo.

A DP foi originalmente concebida na França, na década de 90, da junção de um campo prático (Engenharia de Formação) e três correntes teóricas (conceitualização na ação, psicologia ergonômica e didática das disciplinas) (PASTRÉ, 2011), como detalhado na figura a seguir: 
Figura 2 - Correntes que integram a Didática Profissional

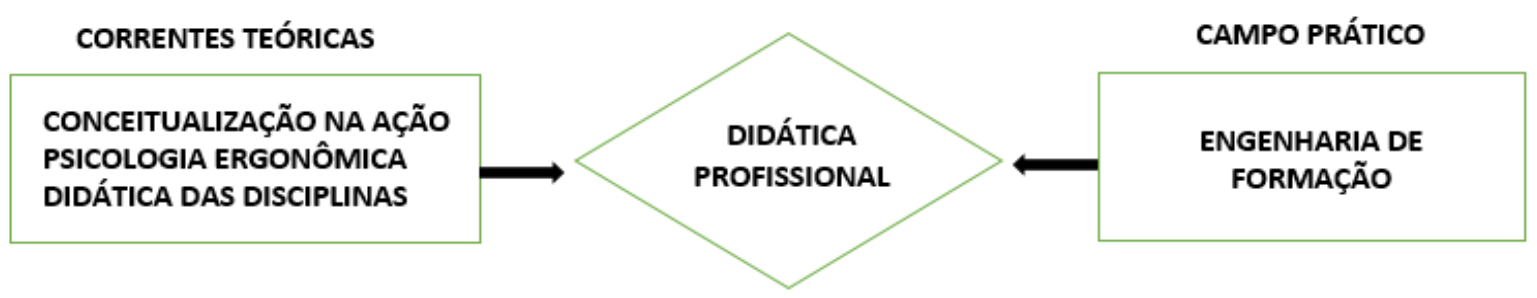

Fonte: Elaboração dos autores (2020).

O objetivo principal da DP é potencializar a aprendizagem nos adultos e aprimorar suas competências profissionais através da análise do trabalho. Conforme Pastré, Mayen e Vergnaud (2006), suas primeiras análises de trabalho foram realizadas no setor industrial, expandindo-se, posteriormente, às atuações de serviço e ensino. Contudo, ela apetece não somente a análise do trabalho, mas também a formação e o treinamento profissional dos adultos (PASTRÉ, 2011). À vista disso, depreende-se que a competência profissional pode e deve também ser analisada no desenvolvimento do trabalho docente, uma vez que este é visto como uma espécie de "operário da educação" e, como resultado, um trabalhador e significativo propulsor do papel social (ALVES, 2019). Alves e Jucá (2019, p. 109) assinalam que:

\begin{abstract}
A partir de um modelo metafórico de automatização do trabalho, podemos compreender que, atualmente, a eficiência ou competência do professor se origina de uma capacidade, cada vez mais tácita de agir e reagir aos incidentes e situações (problemas) escolares erráticas e inéditas. Por conseguinte, podemos adquirir um entendimento de que ser competente significa a capacidade de gerenciar, cada vez mais, situações cada vez mais complexas e não triviais, todavia, recorrentes e invariantes no sistema escolar e, de modo particularmente importante, no interior da sala de aula de Matemática.
\end{abstract}

Portanto, é viável considerar que, conciliando os pressupostos da DP ao ensino da matemática, torna-se concebível aplicar seus princípios às práticas do professor, auxiliando na compreensão da práxis docente e, como resultado, promovendo uma melhoria em torno da ação e atividade do professor de matemática no cenário da educação básica brasileira. Descartando uma discussão exaustiva de todos os elementos conceituais da DP, a seguir serão apresentadas algumas ideias que correlacionam de maneira mais restrita a alguns dos princípios da Didática da Matemática e que propiciam extrair uma repercussão sobre a atividade docente.

A conceitualização na ação parte do princípio que o conhecimento está sistematizado em campos conceituais, cujo domínio, por parte do sujeito, realiza-se progressivamente por meio da prática, maturidade e aprendizagem (PASTRÉ; MAYEN; VERGNAUD, 2006). A atribuição da conceituação na ação se fundamenta "a partir do interesse pelas entidades abstratas associadas ao processo de organização da ação e, no caso da (DP), nos referimos à ação e atividade do profissional e, de forma particular, da ação do professor" (ALVES, 2019, p. 265). Pastré, Mayen e Vergnaud (2006) complementam que os adultos se aperfeiçoam ao longo de sua experiência profissional e durante o treinamento inicial e contínuo que recebem. Dentro do cenário de interesse, ratificam-se as afirmações prévias, mencionando o papel do professor que, por sua vez, aprimora suas capacidades a partir da atuação em sala de aula, consolidado pelas situações desafiadoras que vivencia no decorrer de sua jornada profissional. 
A psicologia ergonômica é formada por um agrupamento de conhecimentos psicológicos relativos à análise e à solução de problemas ergonômicos (estudo da adequação do trabalho ao ser humano). Assim, este campo teórico foi responsável por desenvolver os principais recursos e formulações para a análise do trabalho (PASTRÉ, 2011), dentre eles: a distinção entre tarefa prescrita (aquilo que o profissional deve realizar) e tarefa real (aquilo que o profissional efetivamente realiza); a presença do aspecto cognitivo em todas as atividades laborais, até mesmo no trabalho manual; a distinção entre imagem cognitiva (descreve o objeto em totalidade de suas propriedades, independentemente de qualquer ação) e imagem operativa (representa o objeto apenas com suas propriedades relevantes à ação a ser executada nele) (PASTRÉ, 2011); e o dinamismo das situações, fazendo com que estas evoluam mesmo sem a ação direta do trabalhador. (PASTRÉ; MAYEN; VERGNAUD, 2006).

A Didática das disciplinas aborda vários conceitos fundamentados na Didática da Matemática, tais como a situação didática, transposição, contrato, esquema e campo conceitual. Alguns destes elementos serão mencionados novamente mais à frente.

A Engenharia de Formação, como campo prático da DP, originou-se nos últimos anos da década de 80, a partir de discussões relacionadas a pontos de vista diferentes relativos à Engenharia Didática clássica (ED). Foi apresentada como um recurso para o ensino e formação de professores e nomeada de "Engenharia Didática de Formação (EDF), de desenvolvimento ou Engenharia de 2a geração" (ALVES; CATARINO, 2017, p. 126). Almouloud e Silva (2012, p. 32) declaram que "a engenharia de desenvolvimento está fortemente ligada às investigações nos saberes matemáticos necessários aos professores para ensinar a matemática. É neste sentido que ela está ligada à formação". Pastré, Mayen e Vergnaud (2006, p. 146-147) reportam que:

[...] a engenharia de formação se concretiza, principalmente, a partir de duas práticas: análise das necessidades e dos dispositivos de formação. Pois, tais adultos são, de modo inicial, pessoas que trabalham e, quando decidem realizar uma formação, a mesma é habitualmente conveniente ao trabalho, e não a partir de recortes disciplinares que, geralmente não possuem sentido para os mesmos.

Indubitavelmente, pelos excertos anteriores, percebe-se a existência de um forte interesse na observação da práxis docente e um grande empenho na prática de formação de professores em relação aos objetivos de uma EDF, porém preservando permanentemente a devida importância para o ensino/aprendizagem. (ALVES; DIAS, 2017). Por último, é importante destacar que, por ser uma generalização da Engenharia Didática de $1^{\text {a }}$ geração (clássica), a EDF segue as mesmas fases da ED, que são: as análises preliminares; concepção e análise a priori; experimentação; e análise a posteriori e validação (ARTIGUE, 1988). Todavia, é importante salientar que este trabalho não abordará todas as fases aqui mencionadas, visto que, por tratar-se de uma pesquisa de abordagem qualitativa de dados bibliográficos para uma futura pesquisa de mestrado, o objetivo principal deste é discorrer apenas acerca da concepção (e não da implementação) de uma proposta didática, fundamentada pelas duas primeiras fases da EDF.

Ainda no contexto da Didática Profissional, ao passo que a TSD tem foco principal no desenvolvimento da aprendizagem do aluno, diante da elaboração de sequências didáticas de ensino, e considerando o trinômio professor - aluno - conhecimento, a DP, com atenção voltada para a aprendizagem do profissional/professor, considera como elementos que compõem um cenário de análise laboral, especialmente no cenário da atividade docente, o quatriênio: atividade - situação - aprendiz - formador (ALVES; JUCÁ, 2019). A figura a seguir mostra, 
com mais clareza, os dois cenários aqui mencionados e seus agentes envolvidos neste processo de interação com as situações, onde a figura da esquerda representa o triângulo didático clássico de Brousseau (1986 apud Almouloud, 2007), com seus devidos personagens; e a figura da direita mostra o tetraedro de Baudouin (1999), indicando os elementos considerados nas relações investigativas da DP:

Figura 3 - Triângulo didático das situações de ensino e tetraedro das situações didáticas de trabalho.

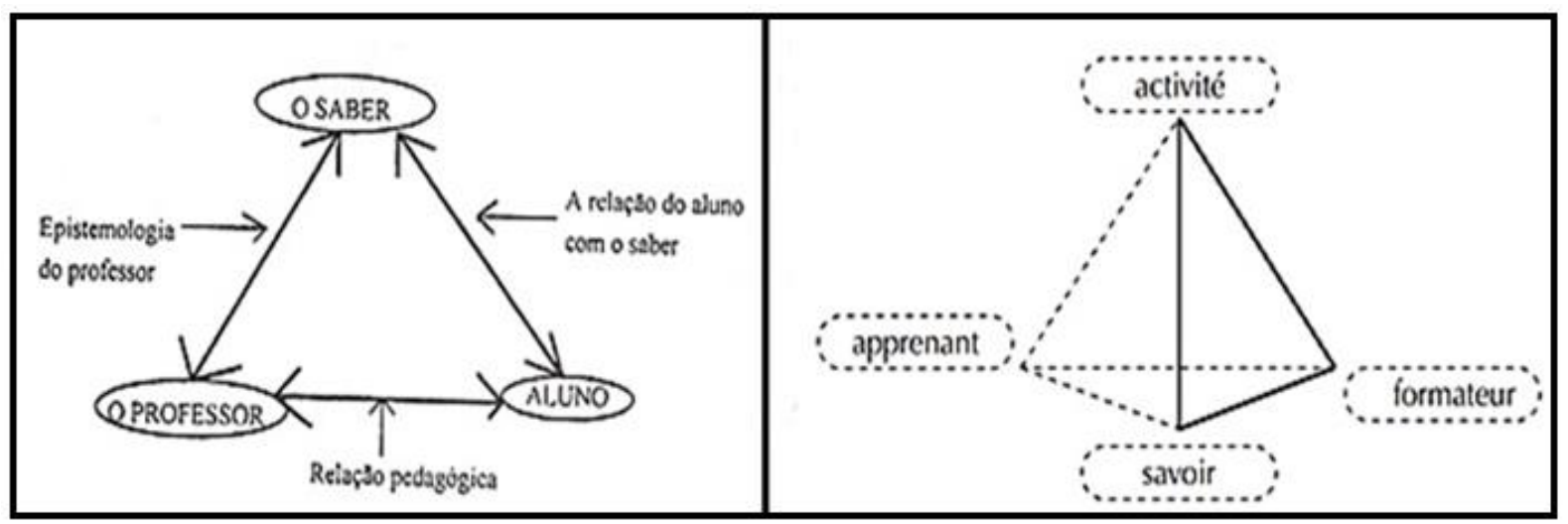

Fonte: Almouloud (2007, p. 32) e Baudouin (1999, p. 152).

Desta maneira, dentro do cenário acadêmico, considera-se que a Didática Profissional revela forte interesse pela atividade do professor, diante de situações de ensino. Assim, a Situação Didática Profissional é indicada por Alves (2018a) como: SDP = UT + DP, onde SDP $=$ Situação Didática Profissional, UT $=$ Unidade de trabalho e DP = Didática Profissional. Ou ainda como:

\footnotetext{
Conjunto de situações ou situação características, fundamental para o exercício efetivo do ofício do professor. Envolve elementos afeitos à modelização e teorização visando antever determinados obstáculos para a atividade sala de aula, para a atividade profissional no posto de trabalho e na própria instituição (ALVES, 2019, p. 269).
}

A unidade de trabalho (UT) se refere ao ambiente principal laboral. No caso do professor, pode ser no campo de atuação da sala de aula, da escola ou ainda da instituição escolar. (ALVES; CATARINO, 2019). A DP, como já proferida, se refere ao cenário ocupacional de ação e inserção do adulto, enquanto profissional, inclusive a do professor. Portanto, a SDP propõe trabalhar a capacitação do professor, mediante situações de aprendizagem, onde o sentido de competência profissional se revelará à medida que o professor supere possíveis obstáculos, diante de tais situações, e revele a sua predisposição de executar, em seu campo de atuação profissional, e em um intervalo de tempo cada vez menor, os desafios cotidianos e constantes do seu trabalho (ALVES; CATARINO, 2019).

Por conseguinte, sustenta-se uma perspectiva nesta pesquisa que pretende compreender a atividade do professor de matemática, diante de um conjunto de situações didáticas, tencionando depreender o desempenho dos artifícios de ensino/aprendizagem deste profissional, diante de obrigações e tarefas determinadas. Ademais, objetiva-se relacionar os pressupostos aqui abordados, com a análise de competência profissional dos professores de matemática no cenário brasileiro a partir da resolução de um problema matemático, direcionado 

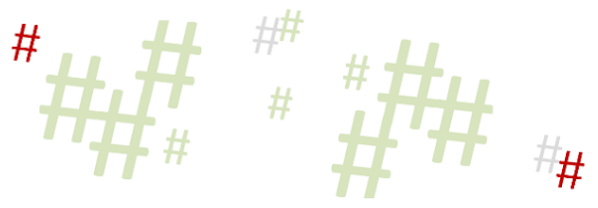

ao SPAECE, possibilitando assim uma maior compreensão da atividade/aprendizagem do docente, relacionadas ao campo epistêmico disciplinar e pragmático.

\section{Representação de uma situação didática com o uso do software GeoGebra}

As provas do SPAECE são elaboradas pelo Centro de Políticas Públicas e Avaliação da Educação da Universidade Federal de Juiz de Fora (CAED/UFJF) e não são acessíveis ao público. Entretanto, a Secretaria da Educação do Estado do Ceará (SEDUC-CE), em parceria com o CAED, divulga anualmente boletins pedagógicos de avaliação, nos quais proporcionam um apoio ao professor de matemática, trazendo, entre outras informações e instruções, sugestões de práticas pedagógicas e de questões para se trabalhar com o aluno em sala de aula, oferecendo assim um suporte didático para a preparação de aulas voltadas para a avaliação. Sendo assim, nesta seção será apresentada uma situação didática, fundamentada em um problema do boletim pedagógico de avaliação do SPAECE, retirado do ano de 2017.

Doravante, certifica-se que a partir deste momento, em consonância com Almouloud (2007, p. 172), que indica que um dos objetivos das análises preliminares é "identificar os problemas de ensino e aprendizagem do objeto de estudo e, delinear, de modo fundamentado, a(s) questão(ões), as hipóteses, os fundamentos teóricos e metodológicos da pesquisa”, deve ser posta em prática a primeira fase da EDF, visto que é preciso realizar um levantamento bibliográfico, seja através de livros, artigos científicos e boletins informativos, em busca de informação de padrões e níveis de desempenho dos alunos, bem como sugestões para a prática pedagógica, dentre outras referências. Com isso, foram verificados os boletins pedagógicos de matemática do SPAECE do ensino médio de 2017, onde foram encontradas vastas informações sobre a trajetória da avaliação, interpretação dos resultados e análises pedagógicas, matriz de referência, escala de proficiência, domínios e competências, padrões de desempenho estudantil, entre outras. Assim, de posse destes dados, tornou-se possível identificar os aspectos epistemológicos, cognitivos e institucionais necessários para o desenvolvimento de uma série de situações a serem vivenciadas na sala de aula (PERRIN-GLORIAN; BELLEMAIN, 2019, p. 59), bem como compreender e aceitar os obstáculos que remetem a postura do aluno diante de uma confrontação matemática. O obstáculo é um conhecimento plausível e inevitável. "Portanto, é inútil ignorar um obstáculo. Deve-se rechaçá-lo de maneira explícita, integrar sua negação à aprendizagem de um conhecimento novo, em particular na forma de contraexemplos. Nesse sentido, é um constitutivo do saber" (ALMOULOUD, 2007, p. 50).

Em seguida, revela-se necessário a execução da segunda fase da EDF (análises a priori), visto que se mostra imprescindível uma pesquisa e seleção do problema a ser trabalhado. Segundo Almouloud (2007), as situações-problema devem ser estruturadas de maneira que desenvolva no aluno a capacidade de agir, se expressar, raciocinar e desenvolver-se por iniciativa própria, apropriando-se assim de novos conhecimentos. É também necessária a execução de um planejamento da situação didática e seguir um plano de ação, previamente definido, para as diferentes fases, sempre objetivando a aprendizagem dos alunos. Desse modo, ao verificar-se os boletins pedagógicos mencionados, foram encontradas diversas sugestões de itens direcionados à avaliação do SPAECE, dentre os quais selecionou-se o que será utilizado para representar a situação-problema proposta, visto que os conteúdos cobrados em tal item são intrínsecos e recorrentes ao currículo do ensino fundamental e médio da educação básica.

Posteriormente, "com o intuito de desenvolver habilidades e competências que permitam os estudantes construírem o conhecimento, a suscitar o raciocínio matemático, a reflexão, a análise e, sobretudo a descoberta através do estímulo de algumas ações" (SANTOS; ALVES, 2018, p. 147), propõe-se adotar a fundamentação teórica da TSD e da DP, em caráter 
de complementaridade mútua, visando alcançar a Situação Didática Profissional e relacionando-as com a formação do professor. Portanto, após escolhido o problema, este será explorado mediante as fases da Teoria das Situações Didáticas, procurando despertar ações que desenvolvam as habilidades matemáticas dos professores em formação inicial ou continuada. Por tratar-se de uma situação voltada para o desenvolvimento das habilidades e competências profissionais do professor, haverá dois personagens neste cenário: o professor/pesquisador (que será chamado de professor) e o professor em formação (a ser nomeado de aluno). Além disso, admitindo-se que o segundo já dispõe de conhecimento dos conteúdos apresentados no problema, pretende-se nesta etapa analisar a ação do professor, sob a perspectiva da TSD, bem como as implicações de alguns conceitos da DP, tratados anteriormente.

Concomitantemente, preconiza-se o uso do software GeoGebra, com o objetivo de vislumbrar a representação gráfica da situação-problema proposta, promovendo assim a transposição didática, designada por Chevallard (1991), como sendo a passagem do saber sábio para o saber ensinado, ou seja, a conversão do conhecimento técnico em conhecimento pragmático. É importante aqui destacar que o professor, ao propor situações didáticas que necessitarão do uso do software GeoGebra, deve elaborá-las de maneira acessíveis à manipulação, induzindo o aluno ao manuseio do aplicativo durante o processo de resolução de futuras situações-problema.

No que concerne à Didática Profissional, cabe aqui relacionar as ações do professor em formação, no decorrer do processo da situação didática, com alguns de seus pressupostos já discutidos anteriormente. Como exemplo, tem-se o desenvolvimento da competência profissional docente perante esta situação desafiadora, caracterizando a conceitualização na ação.

Outra conduta a ser relacionada, é a distinção entre tarefa prescrita e tarefa real. Conforme Therrien e Loiola (2001), à vista do ensino, enquanto atividade, deve-se considerar o desempenho cognitivo dos alunos e o caráter obrigatório da participação destes no ambiente escolar. Ou seja, estes fatores certamente exigirão do professor a realização de ocupações extras (tarefa real), antes do processo de instrução propriamente dito (tarefa prescrita), no intuito de alcançar o envolvimento dos alunos e adaptar os métodos pedagógicos a suas competências simbólicas e cognitivas, conforme exigir a situação.

Mais uma análise a ser feita, antes de dar início à situação proposta, é a diferenciação entre imagem cognitiva e imagem operativa, uma vez que nesta situação é possível analisar o professor em formação neste quesito, ou seja, se ele utilizará de todas as informações (sendo elas relevantes ou não para a resolução da situação), ou se tenderá a considerar apenas as informações significativas à solução do problema.

Por último, mas não menos importante, recomenda-se o estabelecimento de um contrato didático entre o professor/pesquisador e o aluno/professor em formação para um bom funcionamento da situação didática e a fim de evitar mal entendidos e falhas de comunicação, provocados por possíveis divergências de interesses mútuos (PASTRÉ; MAYEN; VERGNAUD, 2006). 
Revista de Educação, Ciência e Tecnologia

\subsection{Situação didática proposta}

Figura 4 - Item retirado do boletim do professor de matemática do ensino médio do SPAECE 2017

Calcule a área do polígono $\mathrm{ABDEC}$ representado no plano cartesiano. (Considere u.c. como unidade de comprimento e u.a. como unidade de área)

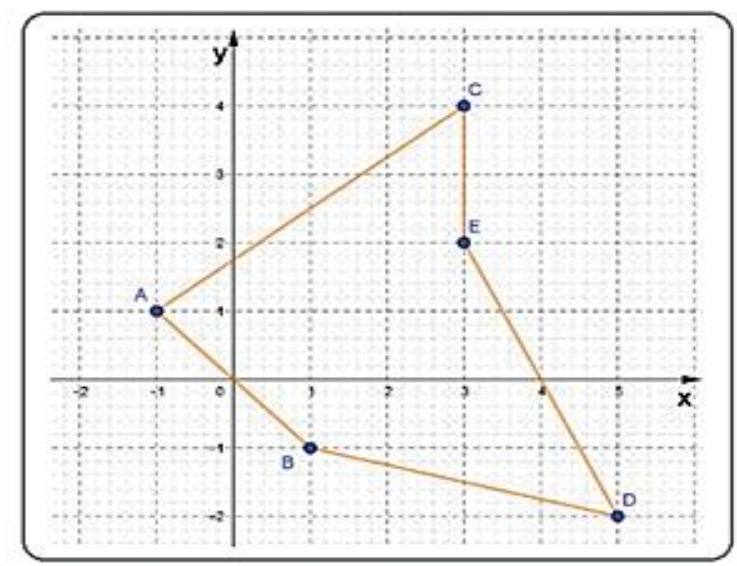

Fonte: Adaptado de CEARÁ, 2017.

Diante do problema exposto na Figura 4, dar-se início à situação de ação, que será o momento em que o aluno/professor em formação irá defrontar-se com o enunciado e as informações contidas no problema. Na ocasião, espera-se que este analise as diversas possibilidades de resolução, explorando a figura no plano cartesiano, observando a medida dos segmentos de cada reta e deduzindo que a área do polígono é a soma dos triângulos: $\mathrm{ACE}, \mathrm{ABE}$ e BDE.

$\mathrm{Na}$ situação de formulação, conforme Almouloud (2007, p. 38), "o aluno troca informações com uma ou várias pessoas, que serão os emissores e receptores, trocando mensagens escritas ou orais". Após ter apresentado a situação-problema e ter esperado a ação dos alunos, o professor/pesquisador poderá sugerir que estes construam a imagem do polígono e a fragmentação de seus respectivos triângulos no GeoGebra, como nas figuras a seguir:

Figura 5 - Representação gráfica do problema 1, dividida em três triângulos.

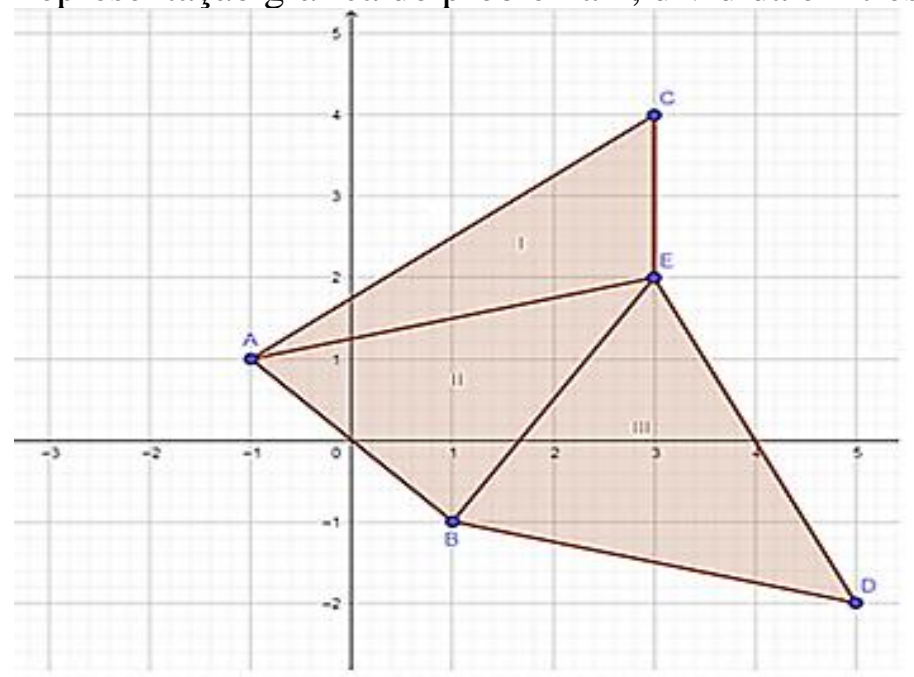

Fonte: elaborado pelos autores (2020). 
Pela Figura 5, fica fácil visualizar que a área do polígono ABDEC será igual à soma das áreas dos triângulos I, II e III. Expressando em forma algébrica, tem-se:

$$
A_{\text {polígono }}=A_{\Delta_{I}}+A_{\Delta_{I I}}+A_{\Delta_{I I I}}
$$

Logo, os alunos, em conjunto ou individualmente, podem manipular a figura construída no software em busca de uma melhor estratégia de resolução. Por exemplo, é possível rotacionar cada triângulo, de modo que sua base fique paralela ao eixo das abscissas, ficando assim mais evidente a visualização dos valores das suas bases e alturas. As figuras a seguir representam tais procedimentos:

Figura 6 - Triângulo I rotacionado em um ângulo de $90^{\circ}$ em sentido horário

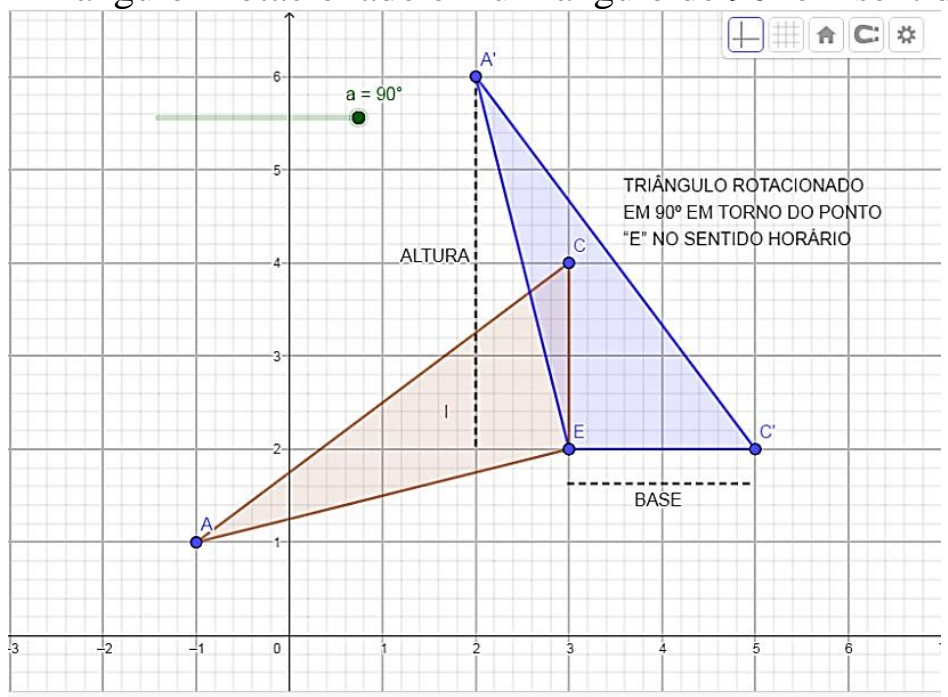

Fonte: elaborado pelos autores (2020).

Figura 7 - Triângulo II rotacionado em um ângulo de $45^{\circ}$ em sentido anti-horário

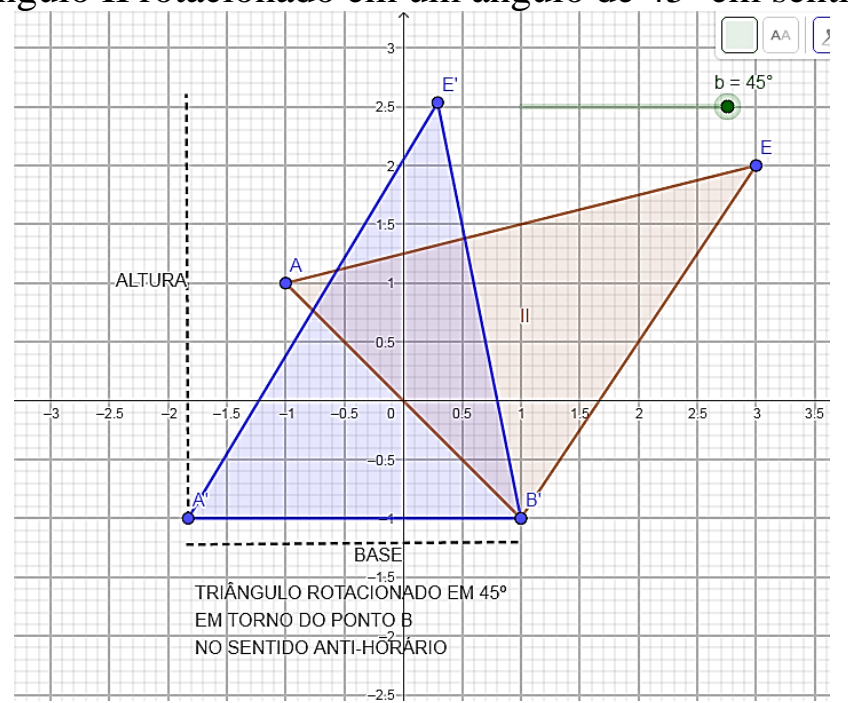

Fonte: Elaborado pelos autores (2020) 
Figura 8 - Triângulo III rotacionado em um ângulo de 14,03 em sentido anti-horário

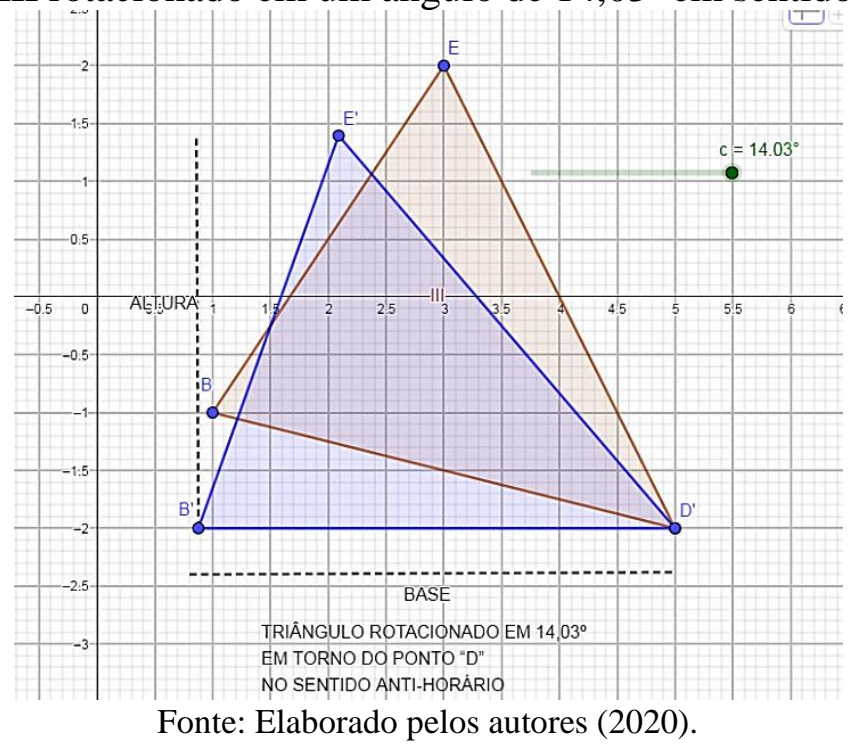

$\mathrm{Na}$ fase de validação, "o aprendiz deve mostrar a validade do modelo por ele criado, submetendo a mensagem matemática (modelo da situação) ao julgamento de um interlocutor" (ALMOULOUD, 2007, p. 39). Nesse caso, almeja-se que o aluno/professor em formação explicite e formalize suas concepções e estratégias para a resolução do problema, podendo estimular uma discussão com os demais alunos. Para tal formalização, o professor em formação deverá mostrar os caminhos percorridos que acarretaram na resolução, utilizando-se de uma linguagem matemática formal por meio de fórmulas matemáticas e, se necessário, utilizando o GeoGebra como complementação de recursos para a certificação de sua resposta.

Finalmente, na fase de institucionalização, "O saber torna-se oficial e os alunos devem incorporá-lo a seus esquemas mentais, tornando-o assim disponível para utilização na resolução de problemas matemáticos" (ALMOULOUD, 2007, p. 40). Ou seja, o aluno oficialmente considera o objeto de conhecimento e o professor leva em conta a aprendizagem do aluno (BROUSSEAU, 2008). Sendo assim, o professor/pesquisador, ao assumir a responsabilidade da situação, poderá instigar os professores em formação a analisarem os aspectos visuais, outrora produzidos no GeoGebra, com os do problema dado, possibilitando uma confrontação entre os modelos adotados. Ou seja, poderão comparar os valores das bases e das alturas e, consequentemente, das respectivas áreas dos triângulos rotacionados, com as dos triângulos em suas posições iniciais. Vale observar que, nos casos em que os triângulos estiverem em suas posições iniciais, será preciso utilizar de alguma fórmula matemática, como o Teorema de Pitágoras, por exemplo, para encontrar os valores de suas medidas. A seguir, estão representados os resultados encontrados nas duas maneiras, para eventual confrontação: 
Tabela 1 - Valores (exatos ou aproximados) das bases, alturas e áreas dos três triângulos que compõem o polígono ABDEC

\begin{tabular}{c|c|c|c|c|c|c}
\hline \multirow{2}{*}{ Triângulo } & \multicolumn{2}{|c|}{ Base (u.c.) } & \multicolumn{2}{c|}{ Altura (u.c.) } & \multicolumn{2}{c}{ Área (u.a.) } \\
\cline { 2 - 7 } & $\Delta_{\text {INICIAL }}$ & $\Delta_{\text {ROTACIONADO }}$ & $\Delta_{\text {INICIAL }}$ & $\Delta_{\text {ROTACIONADO }}$ & $\Delta_{\text {INICIAL }}$ & $\Delta_{\text {ROTACIONADO }}$ \\
\hline I & 2 & 2 & 4 & 4 & 4 & 4 \\
\hline II & 2,8 & 4,1 & 3,6 & 2,45 & 5,04 & 5,02 \\
\hline III & 4,2 & 4,1 & 3,4 & 3,5 & 7,14 & 7,17 \\
\hline
\end{tabular}

Fonte: Elaborado pelos autores (2020).

Nota-se, pela Tabela 1, que os valores das áreas encontrados, em ambas as maneiras, são bem próximos, confirmando assim a confiabilidade do GeoGebra em trabalhar com a percepção visual e manuseio dinâmico de figuras. Ademais, o professor/pesquisador, exclusivamente responsável por esta etapa, deverá rever os conceitos encontrados pelos alunos/professores em formação, realizar a resolução da questão para conferência da linguagem matemática apropriada, bem como de seu rigor técnico/científico, além de unificar as escritas e ideias em uma sentença coerente, considerando os acertos e erros e observando os diferentes caminhos que conduziram para a institucionalização do conhecimento.

\section{Considerações Finais}

Ao iniciar este trabalho, objetivou-se apresentar, através de dados introdutórios de uma vindoura pesquisa de mestrado, uma discussão sobre a prática do professor de matemática no Brasil, assim como apresentar uma proposta de uma situação didática, constituída de um problema direcionado ao SPAECE. Procurou-se considerar a competência profissional docente no âmbito da sala de aula, da escola ou de modo geral, da instituição escolar, levando-se em conta suas limitações, bem como os obstáculos ao processo de evolução profissional, utilizando-se da Didática Profissional, a caráter investigativo, e de como esta se apresenta de modo colaborativo com a formação docente, através de seus pressupostos e das Situações Didáticas Profissionais. Na ocasião, tratou-se das três correntes teóricas que fundamentam tal vertente, utilizando-se de alguns princípios já trazidos pela Didática da Matemática.

Por sua vez, a Engenharia Didática de Formação, que compõe o campo prático da DP, apresentou-se de forma essencial ao papel profissional docente, uma vez que desempenha uma metodologia de pesquisa voltada à atividade do professor, exercendo, neste trabalho, um aporte para a organização da sequência didática indicada através de suas duas primeiras fases. A Teoria das Situações Didáticas, aliada à DP, mostrou-se de grande importância, ao amparar tal investigação direcionada à formação do professor, em especial ao de matemática, fundamentando as suas dialéticas na situação didática proposta que, por sua vez, visou estimular decisões que desenvolvam as habilidades matemáticas dos professores em formação envoltos em uma situação-problema investigativa.

Finalmente, evidenciou-se o uso do software GeoGebra como um amparo significativo na absorção de tais conceitos, ao proporcionar a visualização das figuras da situação-problema, exibindo seus elementos visuais e auxiliando na resolução desta, permitindo ao professor em formação o envolvimento direto na situação, posicionando-se no papel de aluno e reconhecendo os obstáculos no ensino de Matemática, de ordem ontogenética, didática e epistemológica (ARTIGUE, 1989 apud ALVES, 2016b). Ademais, comprovou-se a eficiência do aplicativo 
diante da realização de uma transposição didática, ao auxiliar na prática pedagógica do professor e agregar valores ao saber matemático.

Em conclusão, esperou-se que a discussão de todos estes pressupostos abordados possa vir a contribuir para o desenvolvimento da capacidade profissional docente através da adesão, em sua prática de ensino, de questões voltadas para o SPAECE, aliadas à modelização matemática, através da percepção visual e dinamismo do GeoGebra, e que, por fim, favoreça o professor de matemática, em formação inicial ou continuada, na construção de conceitos e aplicações que possam vir a aprimorar sua prática de ensino.

\section{Referências}

ALMOULOUD, Saddo Ag. Fundamentos da didática da matemática. Paraná: Editora UFPR, 2007.

ALMOULOUD, Ag S.; SILVA, M. J. F. Engenharia didática: evolução e diversidade. Revemat, Florianópolis/SC, v. 7, n. 2, p. 22-52, 2012. Disponível em https://periodicos.ufsc.br/index.php/revemat/article/view/1981-1322.2012v7n2p22/23452. Acesso em: 11 fev., 2020.

ALVES, F. R. V. Didática da Matemática: Seus pressupostos de ordem epistemológica, metodológica e cognitiva. Interfaces da Educação, Paranaíba/MS, v. 7, n. 21, p. 131-150, 2016 a. Disponível em https://periodicosonline.uems.br/index.php/interfaces/article/view/1259/1183. Acesso em: 26 fev., 2020.

ALVES, F. R. V. Engenharia Didática no contexto da Transição Complexa do Cálculo: aspectos epistemológicos e metodológicos sobre a noção de integração de funções. Revista Thema, Pelotas/RS, v. 13, n. 1, p. 47-64, 2016b. Disponível em http://revistathema.ifsul.edu.br/index.php/thema/article/view/322/190. Acesso em: 29 fev., 2020.

ALVES, F. R. V. Didactique de mathématique (DM) el la Didactique Professionnelle (DP): une proposition de complémentarité et la formation des enseignants au Brésil. Imagens da Educação, Maringá/PR, v. 8, n. 3, p. 1-17, 2018a. Disponível em https://pdfs.semanticscholar.org/ff43/9d1bb84fdb791691b4074bb0d389de072a23.pdf?_ga=2.601 07373.1562067456.1585614258-1673186994.1585614258. Acesso em: 17 fev., 2020.

ALVES, F. R. V. Didactique professionnelles (DP): une perspective d'application au travail du professeur de mathématiques. REVEMAT, v. 13, n. 2, p. 184-209, 2018b. Disponível em https://periodicos.ufsc.br/index.php/revemat/article/download/1981-1322.2018v13n2p184/38012. Acesso em: 17 fev., 2020.

ALVES, F. R. V. A vertente francesa de estudos da Didática Profissional: Implicações para a atividade do professor de matemática. Vydia, Santa Maria/RS, v. 39, n. 1, p. 255-275, 2019. Disponível em https://periodicos.ufn.edu.br/index.php/VIDYA/article/view/2459/2326. Acesso em 04 mar., 2020.

ALVES, F. R. V.; CATARINO, P. M. M. Engenharia Didática de Formação (EDF): Repercussões para a formação do professor de matemática no Brasil. Educação Matemática em Revista, Rio Grande do Sul, v. 2, n. 18, p. 121-137, 2017. Disponível em https://pdfs.semanticscholar.org/9493/beccb0074adf115270cb26e0cd9aa5713221.pdf. Acesso em 04 mar., 2020. 
ALVES, F. R. V.; CATARINO, P. M. M. Situação Didática Profissional: Um exemplo de aplicação da Didática Profissional para a pesquisa objetivando a atividade do professor de matemática no Brasil. Indagatio Didactica, Alveiro - Portugal, v. 11, n. 1, p. 103-129, 2019. Disponível em https://proa.ua.pt/index.php/id/article/view/5641/4171. Acesso em 01 mar., 2020.

ALVES, F. R. V.; DIAS, M. A. Formação de professores de matemática: um contributo da engenharia didática (ED). Revemat, Florianópolis/SC, v. 12, n. 2, p. 192-209, 2017. Disponível em https://periodicos.ufsc.br/index.php/revemat/article/view/1981-1322.2017v12n2p192/36380. Acesso em: 11 fev., 2020.

ALVES, F. R. V.; JUCÁ, S. C. S. Trabalho e competência do professor de matemática: um ponto de vista a partir da Didática Profissional. Revista Multidisciplinar em Educação, Porto Velho/RO, v. 6, n. 14, p. 103-123, 2019. Disponível em http://www.periodicos.unir.br/index.php/EDUCA/article/view/3418/2774. Acesso em 15 fev., 2020.

ARTIGUE, M. Ingénierie Didactique. Recherches en Didactique des Mathemátiques, Paris, v.9, n.3, p. 281-308, 1988. Disponível em:

http://www.cfem.asso.fr/actualites/archives/RDM9.3M.ArtigueIngenierieDidactique.pdf/at_downl oad/file. Acesso em 11 fev., 2020.

BAUDOUIN, Jean. M. La compétence et le thème de l'activité: vers une nouvelle conceptualization didactique de la formation. Raison éducative, Genebra, v. 2, n. 2, p. 149-168, 1999. Disponível em: https://bit.ly/2yWSmhP. Acesso em: 01 mar., 2020.

BROUSSEAU, G. Theory of Didactical Situations in Mathematics: Didactique des Mathématiques, 1970-1990. Edição e Tradução de N. Balacheff, M. Cooper, R. Sutherland e V. Warfield. New York, Boston, Dordrecht, London, Moscow: Kluwer Academic Publishers, 2002.

BROUSSEAU, Guy. Introdução ao estudo da teoria das situações didáticas: Conteúdos e métodos de ensino. São Paulo: Editora Ática, 2008.

CARAMELO, J.; SANTOS, M. Vers une reconnaissance des acquis de l'expérience au Portugal. Revue française de sciences sociales, França, v. 6, n. 122, 115 - 137. 2013. Disponível em: https://journals.openedition.org/formationemploi/4002. Acesso em: 10 mar., 2020.

CEARÁ. Secretaria da Educação do Estado do Ceará. SPAECE. Boletim do professor matemática, Juiz de Fora/MG: CAED, 2017.

CHEVALLARD, Y. La transposición didáctica: Del saber sabio al saber enseñado. Traduzido por Claudia Gilman. Buenos Aires: Editora Aique, 1991.

DOUADY, R. Nacimiento y desarrollo de la didáctica de las matemáticas en Francia: rol de los IREM. Artigue, M.; Douady, R.; Moreno, L.; Gómez, P. (eds). Ingeniería Didáctica en Educación Matemática, Bogotá: Grupo Editorial Iberoamérica, p. 1-5, 1995.

MARGOLINAS, C. Situations, savoirs et connaissances...comme lieux de rencontre? Formation et pratiques d'enseignement en questions, Neuchâtel - Suíca, n. 19, p. 31-39, 2015. Disponível em http://revuedeshep.ch/pdf/19/2015-Margolinas-FPEQ-19.pdf. Acesso em 10 mar, 2020. 
MOREIRA, M. A. O mestrado (profissional) em ensino. Revista Brasileira de Pós-Graduação, Brasília/DF, v. 1, n. 1, p. 131-142, 2004. Disponível em http://ojs.rbpg.capes.gov.br/index.php/rbpg/article/view/26/23. Acesso em 07 fev, 2020.

PAIVA, A. C. P.; ALVES, F. R. V. Utilização do GeoGebra como auxílio no ensino de curvatura de curvas planas e espaciais. Revista do Instituto GeoGebra de São Paulo, São Paulo, vol. 7, n. 2, p. 65-79, 2018. Disponível em: http://revistas.pucsp.br/IGISP/article/view/35458/26493. Acesso em: 10 mar, 2020.

PASTRÉ, P. Les compétences professionnelles et leur développement. La Revue de la CFDT, França, 2004. Disponível em: http://www.recherches.philippeclauzard.com/Pastredeveloppementdescompetences.pdf. Acesso em: 28 fev, 2020.

PASTRÉ, P. La didactique professionnelle: Un point de vue sur la formation et la professionnalisation. Education Sciences \& Society, Itália, v. 2, n. 1, p. 83-95, 2011. Disponível em https://riviste.unimc.it/index.php/es_s/article/view/136/65. Acesso em: 28 fev., 2020.

PASTRÉ, P.; MAYEN P.; VERGNAUD G. La didactique professionnelle. Revue française de pédagogie, França, n. 154, p. 145-198, 2006. Disponível em https://doi.org/10.4000/rfp.157. Acesso em 01 mar., 2020.

PERRIN-GLORIAN, M. J.; BELLEMAIN, P. M. B. L'ingénierie didactique entre recherche et ressource pour l'enseignement et la formation des maîtres. Caminhos da Educação Matemática em Revista/Online, Aracaju/SE, v. 9, n. 1, p. 45-82, 2019. Disponível em: https://aplicacoes.ifs.edu.br/periodicos/index.php/caminhos_da_educacao_matematica/article/vie w/298. Acesso em 11 fev., 2020.

SANTOS, A. P. R. A.; ALVES, F. R. V. A Engenharia Didática para o ensino de Olimpíadas de Matemática: Situações olímpicas com o amparo do software GeoGebra. Góndola, Enseñanza y Aprendizaje de las Ciencias, Bogotá, v. 13, n. 1, p.141-154, 2018. Disponível em https://dialnet.unirioja.es/servlet/articulo?codigo=6750763. Acesso em 15 fev, 2020.

THERRIEN J.; LOIOLA F. A. Experiência e competência no ensino: Pistas de reflexões sobre a natureza do saber-ensinar na perspectiva da ergonomia do trabalho docente. Educação \& Sociedade, Campinas/SP, v. 22, n. 74, p. 143-160, 2001. Disponível em http://www.scielo.br/pdf/es/v22n74/a09v2274.pdf. Acesso em: 21 fev., 2020.

Recebido em março de 2020.

Aprovado em maio de 2020. 